proteoglycan concentrations in individual joints examined over time (T Saxne, D Heinegård, and F A Wollheim, unpublished observations). Proteoglycan concentration in synovial fluid appears not to be correlated with fluctuations in traditional signs of inflammatory activity-for example, erythrocyte sedimentation rate, and joint leucocyte count. ${ }^{2}$ Furthermore, it is unlikely that the varying rates of progression observed are due to any therapeutic intervention because neither non-steroidal anti-inflammatory drugs nor other commonly used agents have any effect on the outcome of the disease. $^{5}$

Although selected because they had normal or near normal radiographs of their knees, the patients had an initial median duration of disease of 11 years. Further studies are required to elucidate the prognostic value of proteoglycan measurements in patients with recent onset of disease.

Grants were received from Folksams Yrkesskadors Stiftelse, the Medical Research Council, the Medical Faculty, University of Lund, Kock's Stiftelser, Österlund's Stiftelse, Stiftelsen för Bistånd åt Vanföra i Skåne, Crafoord's Stiftelse, and Konung Gustaf V:s 80-årsfond. We thank Siv Valterson and Annika Björne-Persson for technical help.

1 Saxne T, Heinegard D, Wollheim FA. Therapeutic effects on cartilage metabolism in arthritis as measured by release of proteoglycan structures into the synovial fluid. Ann Rherm Dis 1986;45:491-7.

2 Saxne T, Heinegard D, Wollheim FA. Cartilage proteoglycans in synovial fluid and blood in inflammatory joint disease. Relation to systemic treatment. Arthritis Rheum 1987;30:972-80.

3 Ropes MW, Bennet GA, Cobb S, Jacox R, Jessar RA. Diagnostic criteria for rheumatoid arthritis: 1958 revision. Ann Rheum Dis 1959;18:49-53.

4 Larsen A, Dale K, Eek M. Radiographic evaluation of rheumatoid arthritis and related conditions by standard reference films. Acta Radiol (Diagn) 1977;18:481-91.

5 Pullar T, Capell HA. Can treatment really influence the radiological progression of rheumatoid arthritis? Br $\mathcal{J}$ Rheumatol 1986;25:2-6.

(Accepted 3 September 1987)

University Hospital, S-221 85 Lund, Sweden

TORE SAXNE, MD, PHD, rheumatologist

FRANK A WOLLHEIM, MD, PHD, professor of rheumatology

HOL GER PETTERSSON, MD, PHD, diagnostic radiologist

DICK HEINEGÅRD, MD, PHD, professor of physiological chemistry

Correspondence to: Dr Saxne.

\section{Percutaneous lithotripsy and endoprosthesis: a new treatment for obstructive jaundice in Mirizzi's syndrome}

In 1948 Mirizzi described a syndrome of obstructive jaundice due to impaction of a stone within the cystic duct or the neck of the gall bladder associated with stricture of the common hepatic duct. ${ }^{1}$ The accepted treatment of choledochotomy and cholecystectomy is, however, commonly difficult and hazardous. We report a new treatment consisting of percutaneous lithotripsy and insertion of an endoprosthesis through the papilla of Vater.

\section{Case report}

A previously healthy 71 year old man was referred to this hospital with a three week history of increasing malaise and deepening jaundice. He had a fever and tender hepatomegaly, and his gall bladder was palpable. Biochemical investigation showed a bilirubin concentration of $151 \mu \mathrm{mol} / \mathrm{l}$, indicating obstructive jaundice. Ultrasonography showed dilatation of the biliary tree down to the common hepatic duct with a stone obstructing the neck of the gall bladder, which was dilated. Endoscopic retrograde cholangiography showed the stone adjacent to the stricture of the common hepatic duct with upstream dilatation (figure $(a))$. A $9 \mathrm{~cm} 10$ French gauge $(3.2 \mathrm{~mm})$ polyethylene straight endoprosthesis with side flaps (Amsterdam stent) was inserted through the stricture of the common hepatic duct (figure $(b)$ ) to drain the intrahepatic biliary tree.

Percutaneous drainage of the gall bladder with a 7 French gauge $(2.4 \mathrm{~mm})$ pigtail catheter under ultrasonographic control yielded $300 \mathrm{ml}$ pus. The catheter was exchanged for a 12 French gauge $(4.0 \mathrm{~mm})$ Cope self retaining catheter and left within the gall bladder for two weeks, enabling the patient to return home for a few days. On readmission he had regained weight and was no longer clinically jaundiced (bilirubin concentration $25 \mu \mathrm{mol} / \mathrm{l}$ ).

Subsequently, under general anaesthesia and with radiographic control, the tract into the gall bladder was dilated with fascial dilators and a rigid nephroscope passed through a 26 French gauge Amplatz sheath into the gall bladder. The stone was visualised, a 5 French gauge electrohydraulic lithotripter probe (Wolf Lithotripter 2137, continuous pulse) was applied to its surface, and approximately 100 energy bursts of one second were delivered to induce fragmentation. Fragments were washed out of the gall bladder by saline irrigation around the nephroscope, and larger fragments were extracted with forceps. A

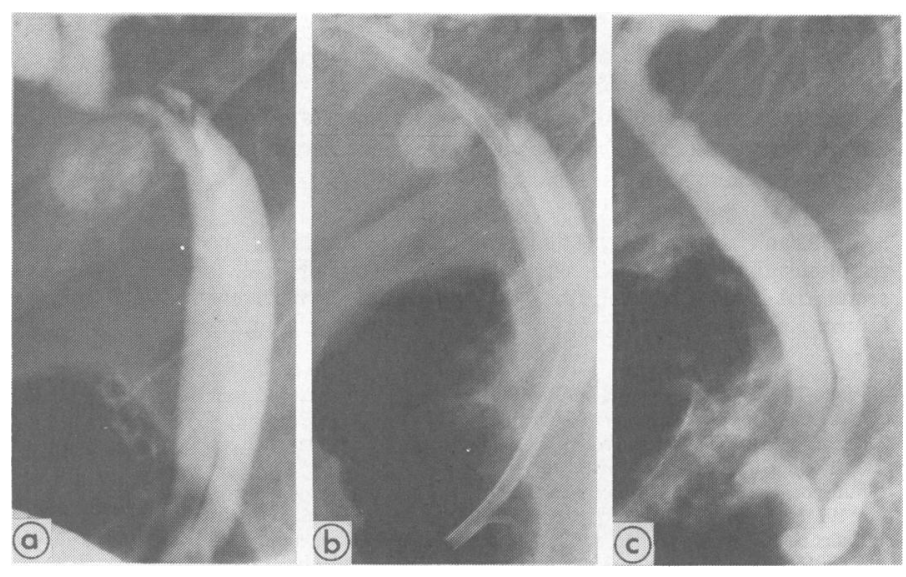

Endoscopic retrograde cholangiograms showing (a) stone adjacent to stricture of common hepatic duct; (b) Amsterdam stent traversing stricture; $(c)$ resolution of stricture. (Ventral portion of pancreas divisum also visible.)

Foley catheter was inserted into the gall bladder before check cholecystography and then removed. The patient was discharged 48 hours after extraction of the stone. Six weeks later the endoprosthesis was removed and a cholangiogram showed complete resolution of the stricture of the common hepatic duct (figure (c)). At endoscopic sphincterotomy a small quantity of sludge was removed from the duct. The procedure was tolerated well by the patient, who was discharged 24 hours later.

\section{Comment}

This patient presented in a confused and toxic state with obstructive jaundice. He was considered to be unfit for surgery and was referred for endoscopic treatment. An endoprosthesis inserted through the papilla of Vater is currently used to treat malignant obstructive jaundice but rarely for benign biliary obstruction and choledocholithiasis. ${ }^{24}$ We were able to avoid the dangers of general anaesthesia and laparotomy by inserting an endoscopic stent to manage the stricture of the bile duct and a percutaneous tube to drain the empyema of the gall bladder.

Alternative methods of managing cholecystolithiasis include percutaneous extraction, the instillation of dissolving agents, and extracorporeal shock wave lithotripsy. ${ }^{5}$ In this case the impaction of the stone within the neck of the gall bladder ruled out the alternatives except for extracorporeal shock wave lithotripsy, which was not available.

We believe this to be the first report of electrohydraulic lithotripsy of a stone within the gall bladder and the use of an endoprosthesis to relieve obstructive jaundice in Mirizzi's syndrome; we suggest that endoscopic and percutaneous treatment should be considered in other such cases.

We thank Mr R C G Russell, Dr R Mason, and Dr D Rickards for advice and help in management and Mrs $M$ Ghilchick for referring the patient.

1 Mirizzi PL. Sindrome del conducto hepatico. Foumal International de Chirurgie 1948;8:731-77. 2 Cotton PB. Endoscopic methods for relief of malignant obstructive jaundice. World f Surg 1984;8:854-61

3 Huigbretse K. Endoscopic treatment of post-operative biliary strictures. Endoscopy 1986;18: 818-22.

4 Dias L, Cairns SR, Cotton PB. Endoscopic prosthesis for common bile duct stones. Gut 1987;28:A1371.

5 Leuschner U. Endoscopic therapy of biliary calculi. In: Classen M, ed. Clinics in gastroenterology. Philadelphia: W B Saunders, 1986:333-58.

(Accepted 9 September 1987)

\section{Middlesex Hospital, London W1N 8AA}

S R CAIRNS, MD, MRCP, senior registrar, department of gastroenterology

G N WATSON, MB, FRCS, senior registrar, department of urology

W R LEES, MB, FRCR, consultant radiologist

P R SALMON, MB, FRCP, consultant gastroenterologist

Correspondence to: Dr Cairns. 